\title{
Erratum to: Introducing IOmi - A Female Robot Hostess for Guidance in a University Environment
}

\author{
Eiji Onchi ${ }^{1}$, Cesar Lucho ${ }^{1}$, Michel Sigüenza ${ }^{1}$, Gabriele Trovato ${ }^{2}$, \\ and Francisco Cuellar ${ }^{1(\bowtie)}$ \\ ${ }^{1}$ Mechatronic Specialty, Engineering Department, Pontificia Universidad \\ Católica del Perú (PUCP), Lima, Peru \\ cuellar.ff@pucp.pe \\ 2 Graduate School of Advanced Science and Engineering, Waseda University, \\ Tokyo, Japan
}

\section{Erratum to: \\ Chapter 75 in: A. Agah et al. (eds.) \\ Social Robotics \\ DOI: 10.1007/978-3-319-47437-3_75}

The original version of the book was inadvertently published without images in Table 1 of Chapter 'Introducing IOmi - A Female Robot Hostess for Guidance in a University Environment'. The erratum chapter and the book have been updated with the changes.

The updated original online version for this chapter can be found at DOI: 10.1007/978-3-319-47437-3_75 